\title{
Percursos da Elaboração de um Problema no Contexto de uma Atividade de Modelagem Matemática
}

\author{
Pathways to a Problem Elaboration in the Context of a Mathematical \\ Modeling Activity
}

\author{
Elenice Josefa Kolancko Setti* \\ ORCID iD 0000-0002-3170-3396 \\ Adriele Carolini Waideman ${ }^{* *}$ \\ ORCID iD 0000-0002-7930-0297 \\ Rodolfo Eduardo Vertuan ${ }^{* * *}$ \\ ORCID iD 0000-0002-0695-3086
}

\begin{abstract}
Resumo
Esta pesquisa, de cunho qualitativo, tem o objetivo de investigar o percurso de elaboração de um problema, a partir de um texto-convite apresentado pelo professor da disciplina de Modelagem Matemática do curso de Licenciatura em Matemática, de uma universidade federal. Para tal, buscamos esquematizar e analisar a verbalização, transcrita, de um grupo formado por três estudantes em formação inicial, enfatizando os indícios do caminho percorrido para realização da atividade proposta. Para subsidiar as análises da investigação, construiu-se o Esquema do Percurso de Elaboração do Problema de Modelagem e o Esquema Interpretativo desse percurso. Dos esquemas, emergiram as categorias: $\mathrm{C} 1$ - A manifestação de que o problema precisa considerar, necessariamente e somente, os dados numéricos apresentados no texto-convite; $\mathrm{C} 2$ - A ideia de que, para elaborar um problema, é preciso identificar um conteúdo matemático que "combine" com as informações da situação; C3 - O entendimento do que é um exercício de Matemática e do que é um "problema" matemático, particularmente, um "problema de Modelagem Matemática" e; C4 - Os gatilhos determinantes da mudança de rumo no percurso de elaboração do problema. Na ação de elaborar um problema passível de investigação, muitas componentes estão envolvidas, desde o entendimento do que seria um problema até a intensidade de envolvimento que o estudante tem com o tema.
\end{abstract}

Palavras-chave: Educação Matemática. Problema de Modelagem. Formação Inicial de Professores.

\footnotetext{
* Mestre em Ensino de Matemática, Universidade Tecnológica Federal do Paraná (UTFPR). Doutoranda em Educação em Ciências e Educação Matemática, Universidade Estadual do Oeste do Paraná (UNIOESTE). Docente da Educação Básica, Técnica e Tecnológica, Instituto Federal do Paraná (IFPR), Assis Chateaubriand, Paraná, Brasil. E-mail: elenice.setti@ifpr.edu.br.

** Mestre em Ensino de Matemática, Universidade Tecnológica Federal do Paraná (UTFPR). Doutoranda em Educação em Ciências e Educação Matemática, Universidade Estadual do Oeste do Paraná (UNIOESTE). Docente do Ensino Fundamental I, Colégio Integrado. Docente colaboradora, Universidade Estadual do Paraná (UNESPAR), Campo Mourão, Paraná, Brasil. E-mail: adrielecarolini@ hotmail.com.

*** Doutor em Ensino de Ciências e Educação Matemática, Universidade Estadual de Londrina (UEL). Professor do Magistério Superior da Universidade Tecnológica Federal do Paraná (UTFPR), Docente Permanente do Programa de Pós-Graduação, Mestrado Profissional, em Ensino de Matemática (PPGMAT - UTFPR), do Programa de Pós-Graduação, Mestrado e Doutorado, em Educação em Ciências e Educação Matemática (PPGECEM - UNIOESTE) e do Programa de Mestrado Profissional em Rede Nacional (PROFMAT - UTFPR), Toledo, Paraná, Brasil. E-mail: rodolfovertuan@utfpr.edu.br.
} 


\begin{abstract}
This qualitative research aims at investigating the elaboration path of a problem, based on a guide given by the professor of the Mathematical Modeling course of the Mathematic Licensure course, at a federal university. To this end, we sought to schematize and analyze the transcribed verbalization of a group formed by three Mathematics Licensure students, emphasizing the signs of the path taken to carry out the proposed activity. To support research analysis, the Modeling Problem Creation Path Scheme and the Interpretative Scheme were constructed. From the schemes, such categories emerged: C1 - The manifestation that the problem needs to consider necessarily and only the numerical data presented on the professor's guide; $\mathrm{C} 2$ - The idea that to create a problem, one needs to identify a mathematical content that "combines" with the situation information; C3 - The understanding of what is a mathematical exercise and what is a mathematical "problema", particularly a "mathematical modeling problema", and; C4 - The triggers that determine the change of direction in the path of problem elaboration. In the action of creating a problem that can be investigated, many components are involved, from the understanding of what would be a problem to the intensity of involvement that students have with the subject.
\end{abstract}

Palavras-chave: Mathematics Education. Modeling Problem. Inicial Teacher Formation.

\title{
1 Introdução
}

Dentre as ações empreendidas pelos sujeitos ao desenvolverem atividades de Modelagem Matemática (MM) na perspectiva da Educação Matemática, está a de elaborar “o problema de Modelagem", ou seja, um problema que abarque aspectos de uma situação que, por algum motivo, interessa responder. Esta ação, ora desempenhada pelo estudante, ora pelo professor, pode tornar-se um dificultador na disseminação da Modelagem ${ }^{1}$, principalmente nas salas de aula da Educação Básica, em que elaborar problemas, não só no contexto da Modelagem, não tem sido ação recorrente. "Nas escolas, nem sempre há espaço para explorar a criatividade assim como a própria formulação de problemas, que também é pouco explorada" (PINHEIRO; VALE, 2013, p. 481).

A literatura sobre Modelagem Matemática (ALMEIDA; SILVA; VERTUAN, 2013; BARBOSA, 2004; BLUM, 2010; BLUM; LEISS, 2007; BLUM; NISS, 1991; BORROMEO FERRI; BLUM, 2010; VERONEZ, 2013, entre outros) considera que no desenvolvimento de uma atividade de Modelagem Matemática a ação de elaborar um problema para investigação é essencial. No entanto, verifica-se, em buscas realizadas na literatura sobre Modelagem, que a discussão sistemática desta ação ainda é incipiente. Todavia, sendo uma ação primordial para o desenvolvimento da Modelagem, influenciando os encaminhamentos da atividade e as competências $^{2}$ cognitivas desenvolvidas pelos alunos, é que tomamos esse aspecto da

\footnotetext{
${ }^{1}$ Neste texto, o termo "Modelagem" tem o mesmo significado que "Modelagem Matemática na perspectiva da Educação Matemática".

2 Entendemos por competência, a capacidade ou aptidão em realizar algo. Uma competência pode envolver diferentes habilidades.
} 
realização das atividades como interesse de pesquisa, mais especificamente, no contexto de formação inicial de professores.

Entendemos ser pertinente a reflexão e a análise dessa etapa do processo - a elaboração de um problema a investigar -, levando em consideração que é importante ao professor em formação inicial ou continuada, que usa MM em sua prática, se sentir confortável tanto ao mediar as ações de alunos que empreendem a elaboração de um problema de Modelagem, quanto com a ação de elaborar um problema propriamente, pois nem sempre aplicará atividades conhecidas da literatura, além do que, até mesmo para adaptar uma atividade, primeiramente, é preciso repensar o problema a ser respondido.

Nesse mesmo contexto, Veronez, Castro e Martins (2018) apresentam uma pesquisa que buscou identificar os aspectos que conduzem o reconhecimento de um problema a investigar nas atividades de MM relatadas nos textos dos anais dos Encontros Paranaenses de Modelagem na Educação Matemática. Os autores observaram uma participação pouco ativa do estudante na ação de evidenciar ou indicar um problema a resolver.

Dalla Vecchia e Maltempi ${ }^{3}$ (2019) também abordam a importância do aprofundamento sobre o entendimento de problema em Modelagem, inferindo que o modo como o problema é determinado pode condicionar os encaminhamentos das situações e o próprio processo de Modelagem.

Segundo Mendonça e Lopes (2015, p. 6), “a problematização é o cerne do processo de modelagem. Sendo assim, essa habilidade deve ser desenvolvida pelo professor para que ele possa elaborar atividades e ajudar seus estudantes a problematizar as situações que desejam investigar". Neste contexto, tendo em vista a importância de compreender os aspectos envolvidos na ação de elaborar um problema de MM e de fomentar práticas com vistas a estes aspectos, esta pesquisa busca responder: Como se dá o desenvolvimento do percurso de elaboração de um problema de Modelagem Matemática por estudantes de um curso de Licenciatura em Matemática?

Entendemos percurso para além da ideia de trajeto ou de caminho percorrido, ou ainda, de uma simples descrição do manifestado pelos estudantes durante o processo de elaboração do problema, buscando, ainda, perceber o não dito e inferir acerca dos gatilhos de reflexão e

\footnotetext{
${ }^{3}$ Esta pesquisa buscou investigar "como se mostra o problema no processo de Modelagem Matemática envolvido na construção de jogos eletrônicos por alunos de um curso de Licenciatura em Matemática", utilizando como principal referencial teórico a visão deleuziana de problema, "que não associa o problema à dúvida nem à pergunta, colocando-o em um estado não atual". Como resultado, os autores apresentaram que o "modo como o problema é determinado condiciona os encaminhamentos das situações desenvolvidas e, consequentemente, o próprio processo de Modelagem Matemática" (DALLA VECCHIA; MALTEMPI, 2019, p. 748).
} 
tomadas de decisão nesse processo, de modo a permitir conhecer as maneiras como os estudantes desenvolvem essa ação no âmbito de um grupo.

A investigação apresentada neste artigo tomou como dados as transcrições dos diálogos empreendidos por um grupo de três alunos durante a elaboração de um problema, no contexto de uma disciplina de Modelagem Matemática em um curso de Licenciatura em Matemática. Buscamos identificar e analisar o percurso vivenciado pelos alunos na ação de elaborar (e decidir por) um problema de Modelagem, tomando como ponto de partida um texto-convite. Entendemos que essa ação de elaboração do problema não é trivial, sendo determinante na constituição de outro percurso, o que segue sua elaboração, o percurso de resolução do problema, influenciando, portanto, a revisão e a construção de conhecimentos matemáticos (MENDONÇA, 1993) ou não-matemáticos.

A seguir, apresentamos o referencial teórico da pesquisa, o encaminhamento metodológico, a identificação e análise do percurso da elaboração do problema de Modelagem, as análises relacionadas e, por fim, as considerações finais.

\section{Compreensões de "problema” na Educação Matemática e na Modelagem Matemática}

No contexto da Educação Matemática, especialmente na sala de aula, a palavra problema é amplamente utilizada para definir um certo tipo de atividade proposta aos estudantes, em que é preciso encontrar uma solução. No entanto, há algumas décadas, pesquisadores como Borasi (1986), já apontavam a necessidade de se ter clareza a respeito da compreensão de problema pois, segundo a autora, nem toda situação trabalhada em sala de aula pode ser assim classificada.

Para Onuchic e Allevato (2011, p. 81), problema "é tudo aquilo que não se sabe fazer, mas que se está interessado em fazer”. Kantowski (1977, p. 163) afirma que "um indivíduo é confrontado com um problema quando encontra uma pergunta que ele não pode responder ou uma situação que ele não consegue resolver usando o conhecimento imediatamente disponível para ele". Neste mesmo contexto, Boavida et al. (2008, p. 15) destacam que

\footnotetext{
tem-se um problema quando se está perante uma situação que não pode resolver-se utilizando processos conhecidos e estandardizados; quando é necessário encontrar um caminho para chegar à solução e esta procura envolver a utilização do que se designa por estratégias. Caso contrário, isto é, se a situação pode ser resolvida utilizando processos para nós conhecidos, repetitivos ou mecanizados, que conduzem à solução, estamos perante um exercício.
}

Schoenfeld (1983) enfatiza que um "problema" só é problema se não se sabe como resolvê-lo. Ressalta, ainda, que se não há surpresas e se o "problema” pode ser resolvido 
confortavelmente por procedimentos familiares, é um exercício. Neste contexto, um aspecto destacado por Boavida et al. (2008) é de que, dependendo dos conhecimentos do indivíduo, a situação pode se configurar um problema ou não, já que ele mobiliza diferentes competências para a resolução - recurso à memória ou a descoberta de um novo caminho.

Deste modo, entendemos que uma determinada situação caracteriza-se como um problema quando não conhecemos de imediato os procedimentos para resolvê-la, ou seja, quando precisamos descobrir um caminho de resolução.

A partir do entendimento do que se caracteriza um problema na Educação Matemática, estendemos nossa reflexão para o foco desta investigação que é a Modelagem Matemática, que pode ser entendida como "uma alternativa pedagógica em que se aborda, por meio da Matemática, um problema não essencialmente matemático" (ALMEIDA; SILVA; VERTUAN, 2013, p. 17). Neste contexto,

\begin{abstract}
uma atividade de Modelagem Matemática pode ser descrita em termos de uma situação inicial (problemática), de uma situação final desejada (que representa uma solução para a situação inicial) e de um conjunto de procedimentos e conceitos necessários para passar da situação inicial para a situação final (ALMEIDA; SILVA; VERTUAN, 2013, p. 12).
\end{abstract}

De acordo com Almeida, Silva e Vertuan (2013), uma atividade de Modelagem Matemática tem origem em uma situação problemática. Neste sentido, “o primeiro passo é reconhecer a existência de um problema real" (MEYER; CALDEIRA; MALHEIROS, 2011, p. 27). Assim, entendemos que o problema de Modelagem é aquele que emerge de um contexto não necessariamente matemático e deve envolver dados autênticos deste contexto. Sua solução envolve a obtenção de um modelo matemático ${ }^{4}$ a partir de estudo, pesquisa e reflexão do tema. Portanto, não há Modelagem sem um problema de Modelagem!

Deste modo, a ação de elaborar um problema no contexto da Modelagem Matemática se caracteriza como uma situação primordial. No entanto, por sua vez, a ação de elaborar problemas, em qualquer contexto, não se configura como uma ação trivial.

Dependendo das características da atividade de Modelagem, do caso (BARBOSA, 2004) ou do momento da atividade (ALMEIDA; DIAS, 2004), o problema pode ser elaborado e proposto pelo professor; o problema pode ser elaborado e proposto em conjunto entre professor e estudantes; ou ainda, o problema pode ser elaborado e proposto pelos estudantes. Em todas essas situações, há o envolvimento de questões e de aspectos relacionados à elaboração do problema de Modelagem, tais como delimitação do tema; pensar em um

\footnotetext{
${ }^{4}$ Uma representação simplificada da realidade sob a ótica daqueles que a investigam (ALMEIDA; DIAS, 2004; ALMEIDA; SILVA; VERTUAN, 2013).
} 
problema que, de fato, desencadeie uma investigação, entre outros. Dito de outro modo, a própria ação de elaborar um problema constitui-se um "problema" a ser resolvido no desenvolvimento da atividade de Modelagem.

$\mathrm{Na}$ fase de elaborar o problema de Modelagem, o sujeito, ao se dedicar a essa elaboração, desenvolve competências importantes como a "capacidade de articular os dados e formular problemas provindos da situação pesquisada" e ainda "a capacidade cidadã de traduzir e transformar situações do cotidiano em situações matemáticas, para quantificar uma situação e, nas ciências sociais e humanas, buscar as soluções que muitas vezes não são matemáticas, mas de atitudes e comportamento" (BURAK; KLÜBER, 2011, p. 50).

Todavia, Sant'ana e Sant'ana (2009) identificaram em uma turma de licenciandos em Matemática que, ao elaborarem "perguntas", os estudantes apresentaram a tendência de formular questões mais fechadas, isso devido ao fato de terem vivenciado a pedagogia da resposta $^{5}$ no Ensino Médio. Os autores manifestaram a necessidade de os estudantes de um curso de licenciatura terem maior contato com ambientes de aprendizagem que favoreçam o questionamento aberto.

Neste sentido, entende-se como importante desenvolver as capacidades destacadas por Burak e Klüber (2011) em futuros professores, em professores em atuação e nos estudantes da Educação Básica e Superior. Para além de utilizar a Modelagem como veículo (GALBRAITH, 2012) para o aprendizado de conteúdos matemáticos ou não matemáticos, trata-se de utilizá-la como conteúdo (GALBRAITH, 2012), quando o sujeito desenvolve a competência de modelar, que envolve o desenvolvimento e requerimento de outras diferentes competências, dentre elas a de pensar e elaborar o problema de investigação (ALMEIDA; ZANIN, 2016).

Neste aspecto, em sua formação, seja inicial ou continuada, é sugerido que o professor vivencie todas as etapas do processo de Modelagem - escolha do tema, interação, levantamento de hipóteses, seleção de variáveis, matematização e validação - antes de iniciar o desenvolvimento de atividades de Modelagem com seus estudantes (ALMEIDA; SILVA; VERTUAN, 2013; CHAVES; ESPÍRITO SANTO, 2011). Deste modo, terão a oportunidade de aprender sobre Modelagem, aprender por meio da Modelagem e ensinar usando Modelagem (ALMEIDA; SILVA; VERTUAN, 2013).

\footnotetext{
${ }^{5}$ Pedagogia da resposta não oportuniza o desenvolvimento da criatividade, é uma negação da invenção (FREIRE; FAUNDEZ, 1985).
} 


\section{Encaminhamento metodológico}

Os dados utilizados nesta investigação foram produzidos por meio de gravações de áudio, em um dia de 4 horas/aulas, de estudantes do $7^{\circ}$ período que cursavam a disciplina de Modelagem Matemática I, de um curso de Licenciatura em Matemática de uma universidade pública do oeste do Paraná. O professor da disciplina, um dos autores deste artigo, propôs, no primeiro dia de aula, que os alunos se dividissem em grupos e a partir de três "textos-convites"6, entregues em etapas, elaborassem problemas de Matemática a partir das seguintes motivações: “Quais são os problemas que vocês podem responder baseados em cada texto-convite? O que cada texto lhes inspira? O que vocês precisam saber para responder o problema construído? Terão dados suficientes? Do que vocês precisam ir atrás? Pensem em vários problemas, tenham uma chuva de ideias". Nesse momento da disciplina a intenção era a elaboração de problemas de Modelagem Matemática que seriam adotados pelos estudantes para investigação no decorrer de um bimestre.

Os áudios dos diálogos dos grupos foram gravados e transcritos, pois, segundo Barbosa (2007), é relevante focar nos discursos produzidos nas práticas de Modelagem, pois é através deles que as ações se legitimam.

Por limitação de espaço, para este artigo, optamos por analisar o diálogo de um grupo, escolhido aleatoriamente, composto por três estudantes, quando trabalhavam na elaboração de problemas do primeiro texto-convite intitulado "Cai índice de infestação da dengue em Toledo"

A partir das transcrições destes áudios, buscamos investigar como os estudantes elaboraram problemas motivados por um texto-convite, neste caso, uma reportagem do município em que fica a universidade. A investigação foi orientada pela seguinte questão: Como se dá o desenvolvimento do percurso de elaboração de um problema de Modelagem Matemática por estudantes de um curso de Licenciatura em Matemática?

O método de análise dos dados que estabelecemos (Quadro 1) é composto por quatro etapas: 1. Reconhecimento do corpus; 2. Internalização; 3. Interpretação do corpus e 4. Análise do Esquema de Percurso de Elaboração.

$\mathrm{Na}$ etapa de Reconhecimento do corpus, realizou-se a transcrição do áudio e a leitura prévia desta transcrição. O próximo passo foi a Internalização das ações empreendidas pelos

\footnotetext{
${ }^{6}$ Chamamos de texto-convite os textos do tipo reportagem entregues aos estudantes.

${ }^{7}$ Disponível em: https://www.toledo.pr.gov.br/noticia/cai-indice-de-infestacao-da-dengue-em-toledo. Acesso em: 11 mar. 2019.
} 
estudantes por meio da releitura (por diversas vezes) do corpus, tentando inferir acerca dos seus processos cognitivos e o destaque dos trechos em que manifestavam ideias primárias ou ações que poderiam contribuir com a elaboração do problema, por nós denominadas unidades de elaboração.

À medida que as ações eram internalizadas, ocorria o processo de Interpretação do corpus, para então construir o Esquema do Percurso de Elaboração. Para sintetizar o Esquema do Percurso de Elaboração, construiu-se o Esquema Interpretativo. Por fim, realizou-se a análise dos dois esquemas, construindo categorias a partir da convergência das ações dos estudantes.

\begin{tabular}{|l|l|}
\hline \multicolumn{1}{|c|}{ ETAPAS } & \multicolumn{1}{c|}{ SUBETAPAS } \\
\hline \multirow{2}{*}{ 1. Reconhecimento do corpus } & 1.1 Transcrição dos áudios \\
\cline { 2 - 2 } & 1.2 Leitura prévia das transcrições \\
\hline \multirow{2}{*}{ 2. Internalização } & 2.1 Releitura do corpus \\
\cline { 2 - 2 } & 2.2 Destaque das unidades de elaboração \\
\hline \multirow{2}{*}{ 3. Interpretação do corpus } & 3.1 Construção do esquema do Percurso de Elaboração \\
\cline { 2 - 2 } & 3.2 Construção do esquema interpretativo \\
\hline \multirow{2}{*}{ 4. Análise do Esquema de Percurso de Elaboração } & 4.1 Construção de categorias \\
\hline
\end{tabular}

Quadro 1 - Etapas do método de análise

Fonte: Elaborado pelos autores (2020)

O Percurso de Elaboração (Figura 1) considera retângulos de quatro cores diferentes rosa, azul, amarelo e verde - para diferenciar as ações estabelecidas. Os retângulos rosas representam as informações destacadas pelos estudantes e presentes no texto-convite. Os retângulos azuis representam as ideias primárias formuladas pelos estudantes. Consideramos "ideias primárias" aquelas que foram enunciadas pelos integrantes do grupo em um primeiro momento. Já os retângulos amarelos representam as sugestões que influenciaram fortemente a emergência de ideias consideradas pertinentes na elaboração do problema. Por fim, os retângulos verdes representam as mudanças de atitudes dos estudantes no percurso de elaboração, ou seja, os momentos em que mudam os rumos da elaboração dos problemas.

Utilizamos a imagem de uma lâmpada para o que consideramos serem as ideias essenciais na tarefa de elaboração do problema e, para contextualizar o conteúdo dos retângulos, associou-se a eles, falas dos estudantes, destacadas na transcrição do diálogo do grupo. Codificou-se as falas dos estudantes como E1, estudante 1; E2, estudante 2; e E3, estudante 3.

Para auxiliar a compreensão do Percurso de Elaboração e sistematizar sua interpretação, construiu-se, ainda, uma representação do esquema interpretativo mental (Figura 2), com as 
inferências decorrentes do primeiro esquema.

Por fim, buscou-se construir categorias que denotam o modo como este grupo de estudantes olhou para o texto-convite, entendeu a proposta do professor e encaminhou a elaboração do(s) problema(s).

\section{Percurso da elaboração do problema de Modelagem}

Na Figura 1 a seguir, apresentamos o Esquema do Percurso de Elaboração do Problema de MM, construído com base nas discussões empreendidas pelos alunos desde o momento em que o professor apresenta o texto-convite até o momento da socialização do problema elaborado.

O Percurso não tem o objetivo de ilustrar uma ideia ou descrever uma situação, ele é "o texto" na forma de um esquema. Decidiu-se por utilizá-lo para que o leitor possa ter uma ideia global do percurso de elaboração do problema pelos estudantes. No entanto, a construção do Esquema do Percurso de Elaboração do Problema de MM se mostrou primordial para as análises, pois os esforços empreendidos para a sua construção levaram à compreensão do percurso de elaboração dos estudantes. Este percurso é utilizado na elaboração do esquema interpretativo (Figura 2) sob os seguintes aspectos: considerações observadas nas transcrições do diálogo dos estudantes e suposições/inferências dos autores.

A partir das orientações iniciais do professor e da entrega do texto-convite, os estudantes iniciaram o processo de elaboração do problema. De início, realizaram a leitura e releitura da reportagem $^{8}$, destacando imediatamente os dados numéricos apresentados e inferindo ser possível elaborar um problema com as informações numéricas “Dá pra fazer alguma coisa aqui e alguma coisa aqui. Porque é onde tem número" (Transcrição da fala de E1, 2019).

A primeira ideia do grupo foi elaborar um problema envolvendo as informações " $5 \%$ " e "60 localidades" relacionado ao conteúdo "Intervalo de Confiança" - " [...] trabalhar com aquele indi... é, intervalo de significância ou aquele índice, tipo a tem 95\% de certeza, ah eu esqueci do nome" (Transcrição da fala de E1, 2019).

\footnotetext{
${ }^{8}$ Caso tenha interesse em ler a matéria acesse o link: https://www.toledo.pr.gov.br/noticia/cai-indice-de-infestacaoda-dengue-em-toledo.

${ }^{9}$ Teste usado para indicar a confiabilidade de uma estimativa a nível de confiança de $95 \%$ e estudado pelo grupo em algum semestre anterior.
} 


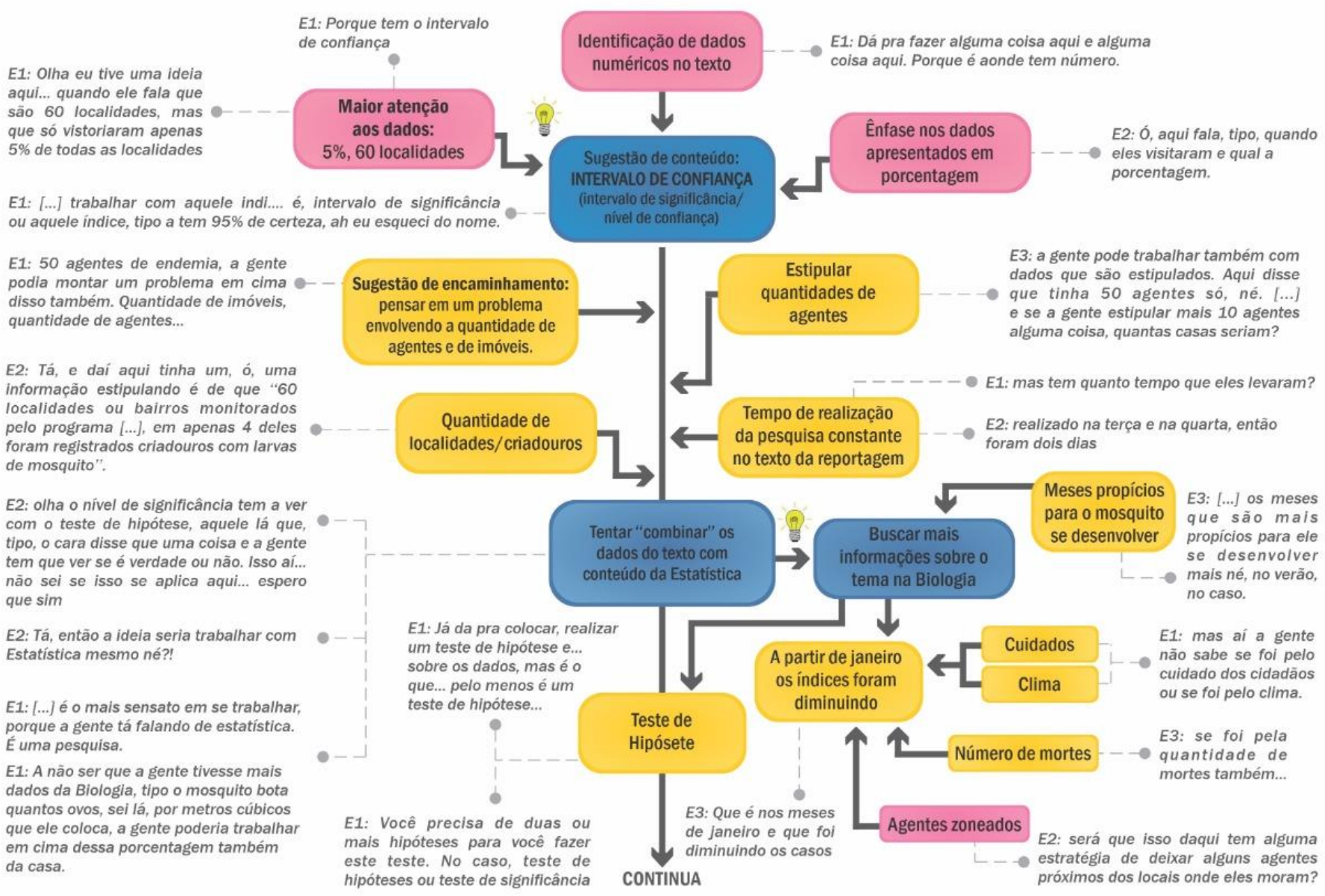

Figura 1 - Percurso de Elaboração do Problema de Modelagem Fonte: Os autores (2020) 


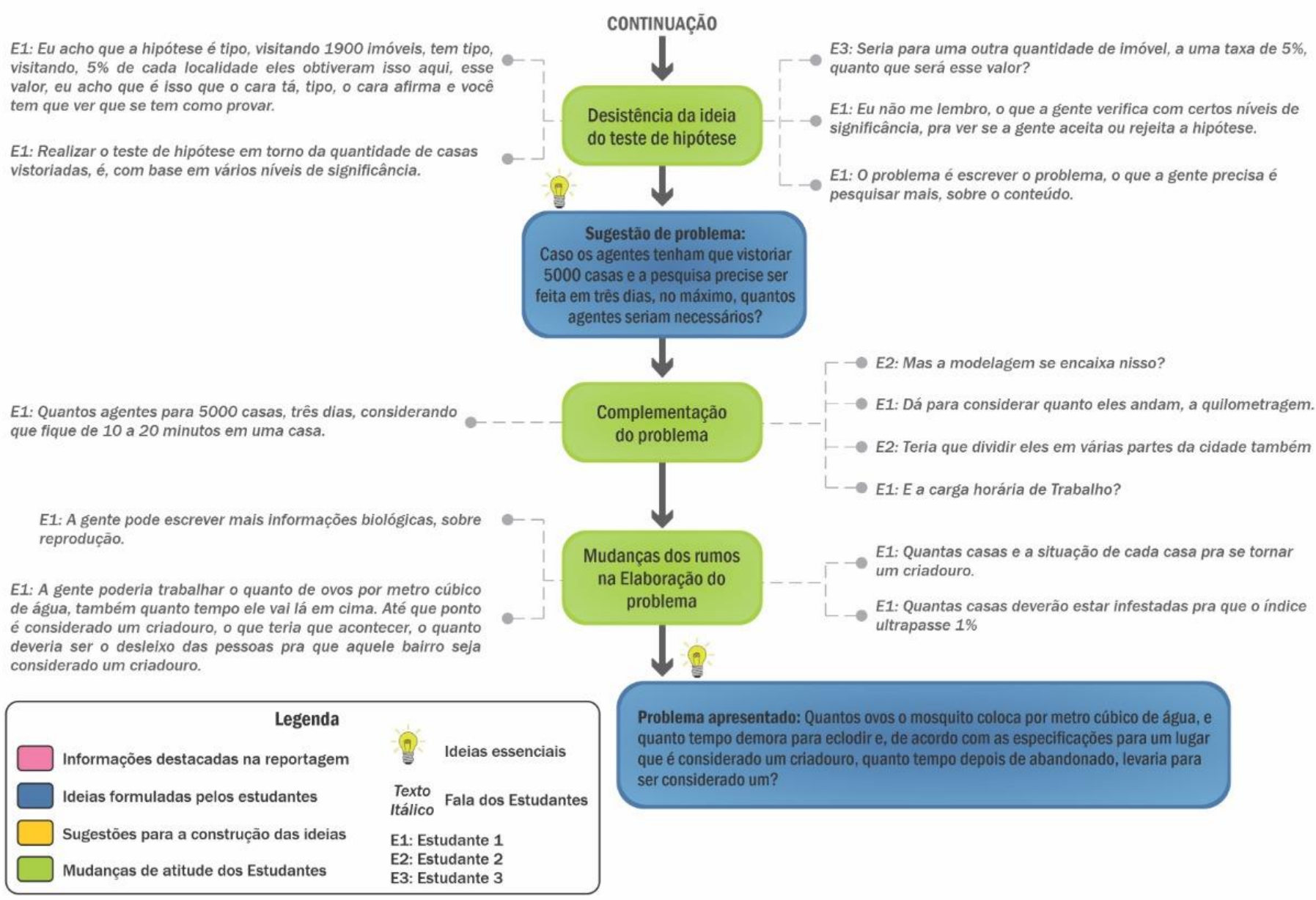

Cont. Figura 1 - Percurso de Elaboração do Problema de Modelagem

Fonte: Os autores (2020)

Acredita-se que, como é uma reportagem, apresenta uma pesquisa e traz a palavra índice, além do dado de 5\% (complementar de 95\%), o estudante E1 fez a associação com o conteúdo da Estatística e convenceu o grupo a "encaixar" um problema envolvendo este conteúdo com as informações numéricas. O grupo permaneceu na ideia de elaboração de um problema envolvendo intervalo de confiança por 18'10" de um total de 40'11".

Continuando o percurso de elaboração, o grupo voltou ao texto-convite, focando agora em outras informações, como, por exemplo, a quantidade de agentes - " 50 agentes de endemia, a gente podia montar um problema em cima disso também" (Transcrição da fala de E1, 2019) - os imóveis visitados, a quantidade de criadouros encontrado nas visitas, os dias e tempo de cada visita.

Algumas informações não constavam na reportagem, porém o grupo trouxe para a discussão hipóteses para a elaboração do problema - "e se a gente estipular mais 10 agentes alguma coisa, quantas casas seriam?" (Transcrição da fala de E3, 2019). O grupo fez diversas 
tentativas, como estipular a quantidade de agentes necessários para realizar visitas em mais casas. Mais uma vez, tentaram encaixar os dados em um conteúdo de Estatística, persistiram que o 5\% que aparecia relacionava-se com "nível de significância" (intervalo de confiança).

Com as discussões no grupo, os estudantes decidiram buscar outras informações, fora do texto-convite, no contexto da Biologia, não descartando os índices apresentados na reportagem, com tentativa de encaixe em "teste de hipótese". Levantaram questionamentos e hipóteses como: quais os meses propícios para o mosquito se desenvolver: "[...] os meses que são mais propicios para ele se desenvolver mais né, no verão, no caso" (Transcrição da fala de E3, 2019); os cuidados tomados pelos cidadãos; a influência do clima; se o número de mortes influenciava na escolha das regiões para as visitas dos agentes de endemias e; sobre a estratégia de deixar agentes zoneados, ou seja, responsáveis pelo território próximo de suas residências.

Aos 21 minutos e 37 segundos de realização desta atividade, o professor avisa aos alunos que em breve disponibilizaria o segundo-texto convite e comenta - "Então, já escrevam as questões". Na sequência, o estudante E2 comenta que para fazer o "Teste de Hipótese" precisaria de duas ou mais hipóteses. Então, o estudante E1 questiona: "eu não posso elaborar um problema... entendeu? Eu acho que a hipótese é tipo, visitando 1900 imóveis, tem tipo, visitando, 5\% de cada localidade eles obtiveram isso aqui, esse valor, eu acho que é isso que o cara tá, tipo, o cara afirma e você tem que ver se tem como provar" (Transcrição da fala de E1, 2019). Os estudantes iniciaram uma conversa sobre a taxa (às vezes chamada de índice) de 5\%, novamente tentando entender o significado disso e o estudante E1 questiona - o que a gente vai verificar? (Transcrição da fala de E1, 2019). Sem um consenso, eles discutiram sobre como utilizar o "Teste de Hipótese": "[...] pra ver se a gente aceita ou rejeita a hipótese. Lembra?" (Transcrição da fala de E1, 2019) - mais um pouco de conversa e o mesmo estudante conclui que "O problema é escrever o problema, o que a gente precisa é pesquisar mais, sobre o conteúdo" (Transcrição da fala de E1, 2019) trecho esse que confirma a inferência feita pelos autores de que eles buscaram, desde o início, elaborar um problema que se encaixasse no conteúdo escolhido.

A terceira ideia para a elaboração do problema focou em uma quantidade de casas vistoriadas pelos agentes. "Caso os agentes tenham que vistoriar 5000 casas e a pesquisa precise ser feita em três dias, no máximo, quantos agentes seriam necessários?" (Transcrição da fala de E1, 2019). Surge uma preocupação com o tipo de problema que está sendo elaborado - “Mas a modelagem se encaixa nisso?” (Transcrição da fala de E2, 2019), ao que o estudante 1 informa que para ser um problema de modelagem precisa apresentar mais detalhes. Mais ideias surgiram para "incrementar" o problema. "Mas calma, a gente pode colocar mais coisa 
nessa questão, por exemplo, tipo 1900, 5000 casas, tipo, quantos agentes para 5000 casas, três dias, considerando que fique de 10 a 20 minutos em uma casa" (Transcrição da fala de E1, 2019). Citaram também a quilometragem que cada agente percorre no dia, a carga horária de trabalho deles e o tempo de visita. "10 a 20 minutos em uma casa" (Transcrição da fala de E1, 2019).

Então, o grupo muda os rumos da elaboração do problema refletindo sobre a quantidade de casas e a situação para se tornar um criadouro - E1: "a gente poderia trabalhar o quanto de ovos por metro cúbico de água, também quanto tempo ele vai lá em cima, até que ponto é considerado um criadouro, tipo, o que teria que acontecer, tipo, o quanto deveria ser o desleixo das pessoas pra que aquele bairro seja considerado um criadouro". Refletiram também sobre a quantidade de casas necessárias para o índice de infestação ultrapassar 1\% e sobre como ocorre a reprodução do mosquito.

A conversa sobre o primeiro texto-convite termina sem um fechamento, porque os alunos recebem o segundo texto-convite. Após a discussão, recebem o terceiro texto-convite ${ }^{10}$. Para finalizar, o professor chamou a todos os grupos para socializarem os problemas elaborados.

O problema apresentado pelo grupo na socialização foi: “Quantos ovos o mosquito coloca por metro cúbico de água, e quanto tempo demora para eclodir e, de acordo com as especificações para um lugar que é considerado um criadouro, quanto tempo depois de abandonado, levaria para ser considerado um?" (Transcrição da fala de E1, 2019).

Percebe-se que os estudantes buscaram encaixar, por diversas vezes, um problema em um conteúdo matemático supostamente conhecido por eles, mesmo mostrando não ter domínio, apenas lembrando alguns conceitos, influenciados pela lembrança que a notação $5 \%$ presente na reportagem trazia. Por fim, apresentaram um problema cujas informações necessárias para sua solução não estavam presentes na reportagem, bem como consideraram um enunciado com detalhamentos que os estudantes julgaram necessários para configurar um problema de MM.

A Figura 2 representa a interpretação do Percurso de Elaboração apresentado na Figura 1. A partir do Esquema Interpretativo, inferiu-se que, após a leitura do texto-convite, os estudantes buscaram por dados numéricos, dando maior atenção aos dados dispostos em porcentagem. A partir daí, buscaram um conteúdo que "combinava" com estes dados. Como a Estatística era algo recente e os estudantes julgaram que os dados do texto combinavam com os

\footnotetext{
${ }^{10}$ Por limitação de espaço, para este artigo apresentamos apenas a análise do primeiro texto-convite. Atenta-se, todavia, que os textos-convite eram cada vez menos elaborados, com menos informações, de modo que os alunos se dedicassem a situações cada vez mais abertas. No dia em questão, os textos-convite abordavam, respectivamente, os temas Desmatamento da Mata Amazônica e Incêndio no Ninho do Urubu - Flamengo.
} 
conceitos de Estatística, elegeram o conceito de "intervalo de significância" e buscaram encaixá-lo na elaboração do problema.

No entanto, apresentaram dificuldades nesta decisão. Então, buscaram "combinar" outros conceitos. Para isso, ousaram ir além dos dados apresentados no texto-convite, buscando informações na Biologia. O grupo ainda fez uma nova tentativa de encaixar o conteúdo de intervalo de significância aos dados, sem sucesso. Devido ao tempo destinado à atividade, desistiram do conteúdo eleito e buscaram elaborar o problema a partir de dados incipientes do texto, mas que poderiam incrementar a partir de buscas e/ou suposições.

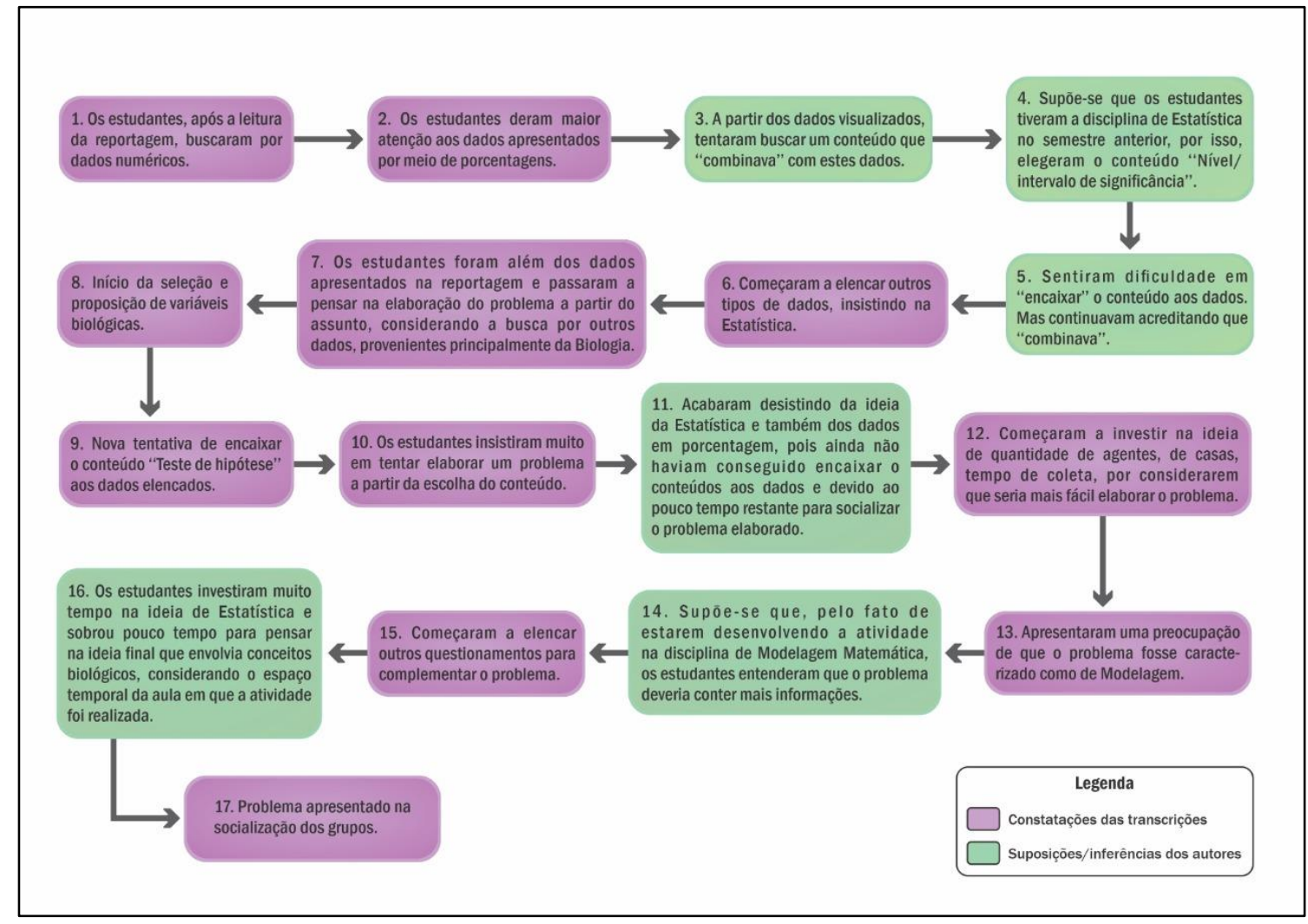

Figura 2 - Esquema Interpretativo

Fonte: Os autores (2020)

Surgiu, então, a preocupação da caracterização do problema como um problema de Modelagem Matemática, pois estavam desenvolvendo a atividade na disciplina de Modelagem Matemática. Assim, inferiram que o problema deveria possuir mais informações, mas o tempo dedicado à elaboração a partir da ideia final pareceu não ser suficiente.

Com a interpretação dos dois esquemas - Percurso de Elaboração e Interpretativo construiu-se quatro categorias de análise: $\mathrm{C} 1$ - A manifestação de que o problema precisa considerar, necessariamente e somente, os dados numéricos apresentados no "texto-convite"; C2 - A ideia de que, para elaborar um problema, preciso identificar um conteúdo matemático que "combine" com as informações da situação; C3 - O entendimento do que é um exercício 
de Matemática e do que é um "problema" matemático, particularmente, um "problema de MM" e; C4 - Os gatilhos determinantes da mudança de rumo no percurso de elaboração.

\subsection{C1 - A manifestação de que o problema precisa considerar, necessariamente e somente, os dados numéricos apresentados no texto-convite}

A partir da proposta de elaborar um problema matemático, os estudantes manifestaram o entendimento inicial de que somente os dados numéricos apresentados no texto-convite deveriam ser considerados: "Dá para fazer alguma coisa aqui e alguma coisa aqui [...] Porque é onde tem número" (Transcrição da fala de E1, 2019). Esta ideia denota a cultura de sala de aula em que os "problemas" matemáticos são, geralmente, limitados aos dados numéricos apresentados na situação, bem como que um problema, para ser matemático, precisa considerar informações numéricas em seu enunciado.

Os estudantes se preocuparam em envolver as informações numéricas na elaboração do problema durante todo o percurso, evidenciando, nas sugestões de problemas elaborados, a intenção de já denotar no enunciado do problema a busca por respostas quantitativas, utilizando termos que remetem a quantidades - quantos agentes, quantos ovos, quanto tempo.

Nas aulas de Matemática da Educação Básica é mais comum trabalhar problemas em contexto fechado, como exercícios, problemas de palavras, problemas de equacionar e demonstrar, reflexo da Pedagogia da Resposta (FREIRE; FAUNDEZ, 1985), enquanto situações mais abertas que envolvem exploração do contexto e criação de problemas são praticamente ignoradas no ensino da Matemática (ABRANTES, 1989; SANT'ANA; SANT’ANA, 2009). Por consequência, "a sua ausência torna a experiência matemática dos alunos consideravelmente limitada e pouco significativa" (ABRANTES, 1989, p. 9).

Neste sentido, como o foco inicial estava em elaborar um problema de Matemática e Matemática envolve números, os estudantes acharam óbvio que o problema deveria envolver números em sua proposição. Mesmo quando E1 sugere buscar mais informações no contexto da Biologia, algumas das informações apresentadas pelos integrantes do grupo continuaram a remeter a quantidades - número de mortes, número de ovos. No entanto, a busca por caracterizar o problema como sendo de Modelagem - "Mas a Modelagem se encaixa nisso?" (Transcrição da fala de E1, 2019) - propiciou o surgimento de reflexões acerca de contextos mais amplos, que não remetiam diretamente aos dados numéricos - cuidados com o quintal, clima, justificativa do comportamento dos dados ao longo dos meses, agentes zoneados.

Neste contexto, como enuncia Abrantes, quando o problema consiste em matematizar 
situações reais, se constitui uma tarefa complexa e imprecisa. No entanto,

\begin{abstract}
A maneira «imprecisa» como o problema é enunciado não deve ser vista como uma fraqueza, mas, pelo contrário, ela constitui uma forma realista de o apresentar. Aqui, é indispensável explorar o contexto do problema (incluindo os seus aspectos não matemáticos), obter informações que não são dadas à partida, formular com precisão novos problemas, proceder a algumas simplificações conscientes (ABRANTES, 1989, p. 7).
\end{abstract}

Neste sentido, torna-se importante que os estudantes percebam que, ao elaborar um problema de Modelagem, não só os dados numéricos são importantes para a elaboração, mas também informações adicionais relativas à biologia, saúde pública, por exemplo, proporcionando reflexão crítica acerca do contexto.

\title{
4.2 C2 - A ideia de que para elaborar um problema, é preciso identificar um conteúdo matemático que "combine" com as informações da situação
}

Os estudantes participantes da pesquisa, ao pensar na elaboração do problema, após encontrar os dados numéricos do texto, buscaram um conteúdo que "combinasse" com esses dados. Ou seja, a tentativa consistiu em montar um "quebra-cabeças" com os dados apresentados, com um conteúdo que combinasse e com o possível problema.

Os conteúdos escolhidos pelos estudantes foram "intervalo de confiança" e "teste de hipótese", ambos da Educação Estatística, porém estes conteúdos e suas resoluções não estavam claramente definidos para os estudantes, pois a informação do texto selecionada por eles - "5\%" - no contexto apresentado, não caracterizava o conteúdo escolhido.

A estratégia de utilizar um conceito matemático conhecido para elaborar um problema denota a tentativa protocolar de lidar com a situação e ter sucesso. "A ação de elaborar um problema está intimamente relacionada à antecipação de sua solução, ou seja, é possível que os alunos pensem na solução do problema como um todo antes mesmo de escrever o seu enunciado" (FONTEQUE, 2019, p. 80). No entanto, o foco do professor era de que os estudantes estivessem preocupados em problematizar uma situação e, na investigação para resolver problemas pelos quais se interessassem, aprendessem ou revisitassem os conceitos matemáticos, conduta esperada no desenvolvimento de atividades de Modelagem.

Neste sentido, o problema começou a tomar forma quando as ações caminharam para a tentativa de se pensar no problema desprendido do conteúdo matemático vislumbrados de imediato. Em Modelagem Matemática, o foco principal está no problema e, em sua solução, os conteúdos e encaminhamentos para resolvê-lo são igualmente importantes, mas não são tomados a priori. Os conteúdos devem estar a serviço do problema e não o contrário. 


\subsection{C3 - O entendimento do que é um exercício de matemática e do que é um "problema" matemático, particularmente, um "problema de Modelagem Matemática"}

$\mathrm{Na}$ proposição da atividade, a intenção do professor era de que os estudantes elaborassem problemas de Modelagem Matemática. Como não houve, propositalmente, uma discussão anterior nesta turma sobre o que seria um problema, o que seria um problema de Matemática e muito menos um problema de Modelagem Matemática ${ }^{11}$, os estudantes levaram em conta os seus entendimentos prévios, por exemplo, de que um problema matemático deveria ter números $(\mathrm{C} 1)$ e deveria envolver necessariamente um conteúdo pré-estabelecido $(\mathrm{C} 2)$.

Mais tarde, um dos integrantes apresenta a preocupação de que o problema precisaria ser de Modelagem Matemática, conforme a orientação inicial do docente. Deste modo, a partir das falas, demonstram o entendimento de que um problema de Modelagem precisaria de mais informações: Mas a Modelagem se encaixa nisso? E1: Mas calma, a gente pode colocar mais coisa nessa questão [...] fica mais elaborado o problema (Transcrição da fala de E1, 2019) $(\mathrm{C} 1)$.

Neste momento, o que os alunos colocam em discussão é a intenção de elaborar um problema com um detalhamento maior. Ou seja, interessados em dar conta da tarefa proposta pelo professor, os estudantes manifestam querer construir um problema original, inédito, e diferente dos problemas que serão elencados por outros grupos. Estes elementos, originalidade e flexibilidade - considerando a ciência dos alunos de que existem diferentes possibilidades de problemas - podem ser caracterizados como aspectos de criatividade e são entendidos como a habilidade de gerar ideias infrequentes ou incomuns para a mesma situação, originalidade, e quando essas ideias pertencem a diferentes contextos ou categorias, flexibilidade (ALENCAR; BRAGA; MARINHO, 2016).

Esta categoria denota a importância da reflexão sobre o que se configura um problema de Modelagem Matemática, que, de acordo com a literatura, é um problema de um contexto extra matemático que envolve informações (ou dados) legítimas do contexto e que desencadeie uma investigação (ALMEIDA; SILVA; VERTUAN, 2013; BARBOSA, 2004). Denota, ainda, que, devido à cultura escolar de lidar com problemas fechados, muitas vezes também com respostas fechadas, diante da rotina de responder problemas e exercícios, e da quase

\footnotetext{
11 A discussão sobre problemas e sobre problemas de Modelagem se deu no momento da socialização dos problemas elaborados pelos estudantes. Todavia, os estudantes já tinham realizado uma primeira conversa coletiva sobre o que consideravam Modelagem Matemática, em aula anterior à da realização dessa atividade.
} 
inexistência de momentos de elaboração de problemas nas aulas, os estudantes tendem a significar "problema de Modelagem Matemática" a partir do que entendem por "exercícios", em um primeiro momento.

Uma possibilidade de ressignificação do entendimento de problema, no contexto das atividades de Modelagem, é a de empreender reflexões como as realizadas na experiência sobre a qual se debruça essa investigação, em que o professor fomentou uma discussão acerca da caracterização de um problema de Modelagem a partir das apresentações dos problemas elaborados por todos os grupos a partir de textos-convites.

\subsection{C4 - Os gatilhos determinantes da mudança de rumo no percurso de elaboração}

No decorrer da atividade, manifestaram-se ações que provocaram mudanças no percurso na elaboração do problema, muitas vezes, embarcando os estudantes em novas ideias. Chamaremos estas ações de gatilhos.

O primeiro gatilho manifestado foi a intenção de vislumbrar outras possibilidades de elaboração, momento em que os estudantes passaram a pensar em informações sobre o tema no contexto da Biologia, rompendo com os limites das informações apresentadas apenas no textoconvite: “A não ser que a gente tivesse mais dados da Biologia, tipo o mosquito bota quantos ovos, sei lá, por metros cúbicos que ele coloca, a gente poderia trabalhar em cima dessa porcentagem também da casa" (Transcrição da fala de E1, 2019). O segundo gatilho, sugestão de E1 em utilizar o teste de hipótese, motivou o retorno a ideia inicial do problema. Mesmo saindo dos limites das informações do texto, os estudantes voltaram a investir na ideia inicial, tentar encaixar o conteúdo de Estatística (Teste de Hipótese) na elaboração do problema. Segundo E1: “Já dá pra colocar: Realizar um teste de hipótese sobre os dados... mas é que eu não me lembro muito bem o que é um teste de hipótese" (Transcrição da fala de E1, 2019).

No terceiro gatilho, influenciados por buscas na internet sobre o conteúdo de Estatística e pela manifestação do professor de que, em pouco tempo iria propor a próxima atividade, os estudantes desistem da ideia inicial e passam a vislumbrar a possibilidade de elaborar um problema com outro foco: "O problema é escrever o problema, o que a gente precisa é pesquisar mais, sobre o conteúdo" (Transcrição da fala de E1, 2019). Isto fez com que os estudantes aligeirassem a conclusão da atividade, com alternativas mais simplificadas. A preocupação que o problema se caracterizasse como sendo de Modelagem, foi o quarto gatilho:

“Mas a Modelagem se encaixa nisso?" (Transcrição da fala de E1, 2019). Este gatilho motivou a tentativa de envolver mais informações na elaboração do problema. 
Acredita-se que os gatilhos acontecem devido ao amadurecimento da situação. Mesmo tendo pouco tempo, os estudantes puderam discutir, pesquisar, fazer suposições. Essas ações só são possíveis em uma atividade em grupo. Embora esse estudo tenha sido realizado no que diz respeito à situação de elaborar um problema, ao tomar essa tarefa como um problema em si, o que podemos vislumbrar é que no enfrentamento de outros problemas, inclusive nos de ordem matemática, a situação dos gatilhos pode se mostrar essencial para compreendermos o encaminhamento das soluções.

\section{Considerações finais}

Ao lançar olhares para o percurso de elaboração de um problema de um grupo de três estudantes que cursavam a disciplina de Modelagem Matemática no curso de Licenciatura em Matemática, evidenciou-se alguns aspectos quanto às suas atitudes frente à situação e aos entendimentos manifestados sobre problema e problema de Modelagem.

Os estudantes não estão acostumados com a ação de elaborar problemas, geralmente precisam resolvê-los e, ainda, a partir de um conteúdo já estudado. Deste modo, elaborar um problema se torna um desafio ainda maior, pois a prática de se elaborar um problema não é trivial. Aspecto observado também por Fonteque (2019) ao investigar a elaboração de problemas por estudantes do Ensino Fundamental.

No decorrer do percurso de elaboração, os estudantes perceberam que os dados numéricos do texto não precisavam aparecer no problema, que poderiam pensar em informações e variáveis a se considerar "fora" do texto-convite. Verificou-se também que a ação de escolher um conteúdo que combinasse com os dados, para então elaborar o problema, se mostrou como um dificultador na elaboração.

O percurso de se elaborar um problema de Modelagem passou primeiro pelo caminho de se elaborar um problema, independentemente de ser de Modelagem ou não. Ao final do percurso de elaboração, os estudantes apresentaram um enunciado, mas ainda inseguros no que diz respeito a se tratar ou não de um problema de Modelagem. A partir das discussões empreendidas na socialização, buscariam adequá-lo à Modelagem, se fosse o caso.

Neste sentindo, na ação de se elaborar um problema, muitos componentes estão envolvidos - 1. componente do conhecimento prévio do que os alunos já sabem da situação investigada e das várias vertentes que podem abarcar e encaminhamentos pelos quais os estudantes podem se enveredar; 2. componente dos entendimentos iniciais, concepções do que seria um problema, um problema de Modelagem, do que seria Modelagem; 3. componente do 
conhecimento matemático, do que se sabe sobre os conteúdos matemáticos que se vislumbra utilizar para investigar a situação; 4. componente do contexto da atividade, como quando os estudantes buscam construir um problema original e diferente do que os outros estudantes apresentarão; 5. componente do trabalho em grupo, no sentido de como as pessoas lidam umas com as outras em uma situação de investigação. A proposta da atividade motivou nos estudantes estas reflexões e ações, mesmo que inconscientes, e elas os influenciaram em seu percurso.

Entende-se que atividades como a apresentada neste artigo têm grande importância na formação do estudante, não só no Ensino Superior, mas na Educação Básica. Os problemas, antes de serem resolvidos, precisam ser bem formulados, com objetivos claros de proposição. A experiência da produção dos dados denota que é importante que os alunos tenham momentos para discutir, especificamente, a elaboração de problemas, o que implica não apenas considerar esta ação como parte do processo, mas também torná-la foco das discussões nas salas de aula. No contexto da Modelagem Matemática para a Educação Matemática, esta ação se torna evidente, já que o ponto de partida de uma atividade neste contexto é a elaboração do problema a partir de um contexto extra matemático, seja pelo estudante, seja pelo professor.

\section{Referências}

ABRANTES, P. Um (bom) problema (não) é (só)... Educação e Matemática, Lisboa, v. 8, n. 35, p. 07-10, 1989.

ALENCAR, E. S. de.; BRAGA, N. P.; MARINHO, C. D. Como desenvolver o potencial criador. 12. ed. Petrópolis: Editora Vozes, 2016.

ALMEIDA, L. M. W. de; DIAS, M. R. Um estudo sobre o uso da Modelagem Matemática como estratégia de ensino e aprendizagem. Bolema, Rio Claro, v. 17, n. 22, p. 19-35, 2004.

ALMEIDA, L. M. W. de; SILVA, K. P. da; VERTUAN, R. E. Modelagem Matemática na Educação Básica. 1 ed. São Paulo: Contexto, 2013.

ALMEIDA, L. M. W. de; ZANIN, A. P. L. Competências dos alunos em atividades de modelagem matemática. Educação Matemática Pesquisa, São Paulo, v. 18, n. 2, p. 759-782, 2016.

BARBOSA, J. C. Modelagem Matemática: O que é? Por que? Como? Veritati, Lisboa, n. 4, p. 73-80, 2004.

BARBOSA, J. C. A prática dos alunos no ambiente de Modelagem Matemática: o esboço de um framework. In: BARBOSA, J. C.; CALDEIRA, A. D.; ARAÚJO, J. de L. (Orgs.). Modelagem Matemática na Educação Matemática Brasileira: pesquisas e práticas educacionais. Recife: Sbem, 2007. p. 161-174.

BLUM, W.; LEISS, D. How do Students and Teachers deal with mathematical Modelling Problems? The example Sugaloaf und the DISUM Project. In: HAINES, C.; GALBRAITH, P. L.; BLUM, W.; KHAN, S. (Eds.). Mathematical Modelling (ICTMA12): Education, Engineering and Economics. Chichester: Horwood, 2007. p. 222-231. 
BLUM, W.; NISS, M. Applied mathematical problem solving, modelling, applications, and links to other subjects - state, trends and issues in mathematics instruction. Educational Studies in Mathematics, Dordrecht, v. 22, n. 1, p. 37-68, 1991.

BORASI, R. On the nature of problems. Educational Studies in Mathematics, Amsterdã, v. 17, n. 2, p. $125-141,1986$.

BORROMEO FERRI, R.; BLUM, W. Insights into Teachers' Unconscious Behaviour in Modeling Contexts. In: LESH, R. et al. (Orgs.). Modeling Students' Mathematical Modeling Competences. New York: Springer, 2010. p. 423-432.

BURAK, D; KLÜBER, T. E. Encaminhamentos didático-pedagógicos no contexto de uma atividade de Modelagem Matemática para a Educação Matemática. In: ALMEIDA, L. M. W. de; ARAÚJO, J. de L.; BISOGNIN, E. (Orgs.). Práticas de Modelagem Matemática na Educação Matemática. Londrina: Eduel, 2011.p. 45-64.

BOAVIDA, A. M. R. et al. A Experiência Matemática no Ensino Básico: programa de formação contínua em matemática para professores dos $1 .^{\circ}$ e $2 .^{\circ}$ ciclos do ensino básico. Lisboa: Direcção-geral de Inovação e de Desenvolvimento Curricular, 2008.

CHAVES, M. I. de A.; ESPÍRITO SANTO, A. O. do. Possibilidades para Modelagem Matemática na Sala de Aula. In: ALMEIDA, L. M. W. de; ARAÚJO, J. de L.; BISOGNIN, E. (Orgs.). Práticas de Modelagem Matemática na Educação Matemática. Londrina: Eduel, 2011. p. 161-180.

DALLA VECCHIA, R.; MALTEMPI, M. V. O Problema na Modelagem Matemática: determinação e transformação. Bolema, Rio Claro, v. 33, n. 64, p. 748-767, ago. 2019.

FONTEQUE, V. B. A criatividade na formulação de problemas de alunos do ensino fundamental I e II: um olhar metodológico em sala de aula. 2019. Dissertação (Mestrado Profissional em Ensino de Matemática) - Universidade Tecnológica Federal do Paraná, Londrina, 2018.

FREIRE, P.; FAUNDEZ, A. Por uma pedagogia da pergunta. 4. ed. Rio de Janeiro: Paz e Terra, 1985.

GALBRAITH, P. Models of Modelling: Genres, Purposes or Perspectives. Journal Of Mathematical Modelling And Application, Blumenau, v. 1, n. 5, p. 3-16, 2012.

KANTOWSKI, M. G. Processes Involved in Mathematical Problem Solving. Journal for Research in Mathematics Education, London, v. 8, n. 3, p. 163-180, may. 1977.

MENDONÇA, M. do C. D. Problematização: um caminho a ser percorrido em Educação Matemática. 1993. Tese (Doutorado em Educação) - Faculdade de Educação, Universidade Estadual de Campinas, Campinas, 1993.

MENDONÇA, L. O.; LOPES, C. E. Planejamento de atividades de Modelagem Matemática: um caminho possível. Em teia, Recife, v. 6, n. 1, p. 1-24, 2015.

MEYER, J. F. da C. de A.; CALDEIRA, A. D.; MALHEIROS, A. P. dos S. Modelagem em Educação Matemática. 3. ed. Belo Horizonte: Autêntica, 2011.

PINHEIRO, S.; VALE, I. Formulação de problemas e criatividade na aula de matemática. In: SEMINÁRIO DE INVESTIGAÇÃO EM EDUCAÇÃO MATEMÁTICA, 24., 2013, Braga. Anais [...]Braga: Apm \& Cied da Universidade do Minho, 2013. p. 481-494.

SANT'ANA, A. A.; SANT'ANA, M. de F. Uma experiência com a elaboração de perguntas em 
Modelagem Matemática. In: CONFERÊNCIA NACIONAL SOBRE MODELAGEM MATEMÁTICA, 6., 2009, Londrina. Anais[...] Londrina: UEL, 2009. p. 1-17. 1 CD-ROM.

SCHOENFELD, A. H. The Wild, Wild, Wild, Wild, Wild World of Problem Solving. For The Learning Of Mathematics, Montreal, v. 3, n. 3, p. 40-47, 1983.

ONUCHIC, L. de La R.; ALLEVATO, N. S. G. Pesquisa em Resolução de Problemas: caminhos, avanços e novas perspectivas. Bolema, Rio Claro, v. 25, n. 41, p. 73-98, dez. 2011.

VERONEZ, M. R. D. As funções dos signos em atividades de modelagem matemática. 2013. 176p. Tese (Doutorado em Ensino de Ciências e Educação Matemática) - Universidade Estadual de Londrina, Londrina, 2013.

VERONEZ, M. R. D; CASTRO, E. M. V. de; MARTINS, M. A. Uma investigação acerca do problema em atividades de Modelagem Matemática. VIDYA, Santa Maria, v. 38, n. 1, p. 223-235, jan./jun. 2018.

Submetido em 25 de Agosto de 2020. Aprovado em 27 de Janeiro de 2021. 